\title{
Cardiorespiratory fitness and future risk of venous thromboembolism
}

Running head: Cardiorespiratory fitness and venous thromboembolism

Line H. Evensen*, Trond Isaksen*†, Sigrid K. Brækkan*†, John-Bjarne Hansen*†

*K.G. Jebsen - Thrombosis Research and Expertise Center (TREC), Department of Clinical Medicine,

UiT The Arctic University of Norway, Troms $\varnothing$, Norway

†Division of Internal Medicine, Troms $\varnothing$, University Hospital of North Norway, Troms $\varnothing$, Norway

\section{Correspondence to:}

Line H. Evensen

K.G. Jebsen Thrombosis Research and Expertise Center (TREC)

Department of Clinical Medicine, UiT The Arctic University of Norway

9037 Tromsø, Norway

E-mail: line.h.evensen@uit.no

Telephone: +4748354095

Word count abstract: 250

Word count text: 3809 


\section{Essentials}

- The relation between cardiorespiratory fitness (CRF) and venous thromboembolism (VTE) is unsure.

- CRF was estimated, and the association between age-predicted CRF and VTE risk was investigated

- Compared to $<85 \%$, a CRF of $85-100 \%$ and $>100 \%$ of predicted was related to $46 \%$ and $67 \%$ lower risk

- The association between CRF and VTE risk was independent of body weight status 


\section{Abstract}

Background: Cardiorespiratory fitness (CRF) is a strong predictor of future arterial cardiovascular disease and premature mortality. However, there is limited data on the association between CRF and the risk of incident venous thromboembolism (VTE).

Objectives: To investigate whether estimated CRF (eCRF) was associated with the risk of incident VTE in a cohort recruited from the general population.

Methods: Participants ( $n=10,393)$ from the sixth survey of the Troms $\varnothing$ Study (2007-08) were included, and incident VTEs were recorded up to December 31, 2016. eCRF was estimated in sex-specific algorithms based on age, waist circumference, resting heart rate and self-reported physical activity. Hazard ratios (HRs) with 95\% confidence intervals (Cls) of VTE according to categories of eCRF were calculated in Cox regression models adjusted for sex with age as timescale. The impact of weight status was evaluated in analyses stratified by weight category.

Results: There were 176 incident VTEs during follow-up. Compared with individuals with eCRF $<85 \%$ of age-predicted, those with eCRF of $85-100 \%$ and $>100 \%$ of age-predicted had $46 \%$ ( $\mathrm{HR} 0.54 ; 95 \% \mathrm{Cl}$ 0.39-0.77) and 67\% (HR 0.33; $95 \% \mathrm{Cl} 0.20-0.54)$ lower VTE risk, respectively. Compared with overweight/obese individuals with eCRF $<85 \%$ of age-predicted, overweight/obese with eCRF $\geq 85 \%$ had $50 \%$ (HR $0.50,95 \% \mathrm{Cl} 0.35-0.74$ ) lower risk, and normal weight individuals with eCRF $\geq 85 \%$ had $55 \%$ (HR 0.45, 95\% $\mathrm{Cl} 0.30-0.68)$ lower risk.

Conclusions: Higher eCRF was associated with lower risk of incident VTE. The association was independent of weight categories, suggesting that higher eCRF may modify the association between obesity and VTE. 


\section{Introduction}

Venous thromboembolism (VTE) occurs in 1-2 per 1000 individuals annually, and is the third most common lethal cardiovascular disease (CVD) after myocardial infarction and stroke [1-3]. VTE is not only a potentially fatal disease, but is also associated with debilitating complications, high recurrence rates, and regarded a significant contributor to the global burden of disease [4-6]. Moreover, with an aging population and a rising prevalence of obesity and cancer, the incidence of VTE is expected to increase in the coming years [7-9]. Identification of modifiable risk factors at the population level is currently a priority to curb the growing burden of VTE.

A wealth of evidence support that regular physical activity is beneficial in the prevention of arterial CVD, some cancers and type-2 diabetes, as well as for increased longevity [10, 11]. Emerging data also support that physical activity is associated with a lower risk of incident VTE [12-15], although there is some controversy in the literature $[1,16,17]$. In a recent narrative review, we summarized the available data, and concluded that the current literature is balanced towards a small beneficial effect of physical activity [18]. Important challenges in research on physical activity include inconsistent definitions, a variety of available instruments, and the reliance on self-reported data $[18,19]$. Combined with differences in study design and populations, these challenges may account for the inconsistent literature on physical activity and VTE risk, and studies utilizing objective assessment strategies are warranted [18].

Cardiorespiratory fitness (CRF) relates to the ability of the circulatory, respiratory and muscular systems to supply and consume oxygen during sustained physical activity, and is quantified as maximal oxygen uptake $\left(\mathrm{VO}_{2 \max }\right)$ in $\mathrm{L} / \mathrm{min}$ or $\mathrm{mL} / \mathrm{kg} / \mathrm{min}[20,21]$. Similar to insufficient physical activity, low $\mathrm{CRF}$ is associated with higher risk and less favorable outcomes in arterial CVD and cancer [22-25]. CRF largely reflects the level of habitual physical activity of an individual, but is also influenced by age, sex, genetic architecture, comorbidities, as well as body size and composition [21, 26]. Although the gold standard for assessment of CRF is through direct measurement of oxygen uptake by ventilatory expired 
gas analysis during a maximal exercise test [27], such testing is time and resource demanding and may not be feasible in clinical- and research settings [22]. Therefore, algorithms have been developed to estimate CRF, and these correlate well with objectively assessed CRF and appear to be robust health indicators [22, 28-30]. Importantly, CRF is reported to be a stronger predictor than physical activity for several health outcomes, such as coronary heart disease and all-cause mortality [31-33].

Two previous studies have addressed the association between CRF and risk of incident VTE. Based on data from a Swedish cohort of male conscripts (aged 18-20 years), Zöller et al. reported that higher weight-adjusted maximal workload on a cycle ergonometric test (Watt $\mathrm{Wax}_{\mathrm{max}} / \mathrm{kg}$ ) was associated with lower risk of unprovoked incident VTE [34]. Further, Kunutsor et al. found a non-significant lower VTE risk in middle-aged (42-61 years) men in the highest tertile of weight-adjusted maximal oxygen uptake assessed on a cycle ergonometric test [35]. A limitation of the former study was that $80 \%$ of the VTEs occurred before the age of 50 (maximal attained age at the end of follow-up was 56 years), whereas both studies were restricted to men only $[34,35]$.Thus, it still remains to be established whether CRF relates to VTE risk, and whether an association is influenced by gender. Therefore, the aims of the present study were (i) to investigate the association between estimated CRF (eCRF) and the risk of incident VTE in a cohort recruited from the general population, and (ii) to explore whether a potential association was influenced by weight as body weight is associated with both CRF and VTE risk $[26,36]$.

\section{Methods}

Study population

The Troms $\varnothing$ Study, initiated in 1974, is a large population-based cohort study with repeated health surveys of the inhabitants of Troms $\emptyset$, Norway. Seven surveys have been completed so far (2019), and the present study was based on 12,981 participants enrolled in the sixth survey in 2007-08. Detailed methodology of the Troms $\varnothing$ Study has been published elsewhere [37]. Briefly, total- or samples of total 
birth cohorts of subjects within the age range 30-87 years were invited, and the attendance rate was $66 \%$. Individuals not officially registered as inhabitants of the Troms $\varnothing$ municipality at baseline $(n=6)$, with a history of VTE $(n=182)$ or with missing data on variables required for estimating CRF (i.e. age, waist circumference, physical activity and resting heart rate; $n=2,400$ ) were excluded. Consequently, 10,393 individuals were included in the analyses. A comparison of included and excluded participants is shown in Table S1. Excluded participants were older, had a larger waist circumference and a less favorable cardiovascular risk profile compared with those included. Additionally, the fraction with higher education was lower, and the prevalence of CVD was higher among the excluded. Excluded participants with data on physical activity were more active compared with the included participants. Notably, such data were only available in 421 individuals, and these appeared to be a young selection of the excluded participants (mean age was $53.9 \pm 13$ years). The study was approved by the Regional Committee for Medical and Health Research Ethics, and all participants provided written informed consent prior to inclusion.

\section{Measurements}

Baseline information was collected from physical examinations, blood samples and self-administered questionnaires. Height, weight, blood pressure and resting heart rate were measured with standardized procedures, as previously described [36]. Body mass index (BMI) was calculated as weight in kilograms divided by the square of height in meters $\left(\mathrm{kg} / \mathrm{m}^{2}\right)$, and participants were classified as normal weight (BMI <25), overweight (BMI 25-29.9) or obese (BMI $\geq 30$ ) [38]. Information on leisuretime physical activity, smoking habits, education and history of cardiovascular disease (CVD; angina pectoris, myocardial infarction and stroke) was obtained from self-administered questionnaires [13, 37]. The questions on physical activity were related to weekly frequency (never, less than once, once, 2-3 times or approximately every day), duration per session ( $<15 \mathrm{~min}, 15-29 \mathrm{~min}, 30-60 \mathrm{~min}$ or $>1$ hour, and intensity (not short-winded or sweaty, becoming short-winded or sweaty or becoming exhausted). 
A summary physical activity index was calculated by multiplying weighted values of the responses to these questions (Table S2) [39]. Data on cancer was obtained from the Cancer Registry of Norway.

Estimated cardiorespiratory fitness

Cardiorespiratory fitness was estimated from sex-specific algorithms based on age, waist circumference, resting heart rate and physical activity index [39]. These algorithms were developed and validated in a Norwegian population-based cohort with a wide age-range (20-90 years), and CRF estimated from this model has been shown to predict cardiovascular and all-cause mortality [28, 40]. The algorithms for estimating CRF (in $\mathrm{mL} / \mathrm{kg} / \mathrm{min}$ ) were [39]:

Women ( $R^{2} 0.56$, standard error of estimate (SEE) 5.14): $74.74-(0.247 \times$ age $)-(0.259 \times$ waist circumference) $-(0.114 \times$ resting heart rate $+(0.198 \times$ physical activity index $)$

Men $\left(R^{2} 0.61\right.$, SEE 5.70): 100.27 - (0.296 × age) - (0.369 × waist circumference - $(0.155 \times$ resting heart rate $)+(0.226 \times$ physical activity index $)$

In addition, the expected CRF ( $\mathrm{CRF}_{\text {pred }}$ ) according to age was calculated for each participant with the formula 55.6 - $(0.328 \times$ age $)$ for women, and $63.6-(0.393 \times$ age $)$ for men [28]. Based on the fraction of age-predicted CRF (eCRF/CRF pred $* 100 \%$ ), the participants were divided into three categories with cut-offs at $85 \%$ and $100 \%$ [28]. eCRF was also expressed as a multiples of the resting metabolic equivalent (MET). One MET is approximately $3.5 \mathrm{~mL} / \mathrm{kg} / \mathrm{min}$, and regarded as a clinically significant change in CRF [22]. Further, the participants were categorized according to sex- and age- (by ten years) specific quintiles into low eCRF $\left(<20^{\text {th }}\right.$ percentile), moderate eCRF $\left(20-60^{\text {th }}\right.$ percentile $)$ and high eCRF $\left(>60^{\text {th }}\right.$ percentile) $[23,28]$. 
Identification and adjudication of venous thromboembolism

Incident VTE events during follow-up were identified by searching the hospital discharge registry, the radiology procedure registry and the autopsy registry at the University Hospital of North Norway (UNN). UNN is the exclusive provider of hospital care and diagnostic radiology in the study region, and the discharge registry comprises both outpatient visits and hospitalizations. Trained personnel reviewed the medical records and adjudicated potential VTE cases. The adjudication criteria were a combination of: signs and symptoms of PE or DVT, presence of a thrombus confirmed by radiology, a diagnosis of PE or DVT in the patient's medical record, and initiation of treatment (unless contraindications were specified). DVTs in the upper and lower extremities and in other locations (e.g. visceral veins) were included. The process of identification and adjudication of VTE events in the Troms $\varnothing$ Study has previously been described in detail [41]

All VTEs were classified according to clinical presentation (i.e. DVT or PE with or without DVT), and according to the presence of provoking factors at the time of diagnosis. An event was classified as provoked in the presence of the following factors: surgery or trauma (within 8 weeks prior to the event), acute medical conditions (acute myocardial infarction, ischemic stroke, or major infectious disease), active cancer, marked immobilization (bedrest $\geq 3$ days, confined to wheelchair, or longdistance travel $\geq 4 \mathrm{~h}$ within the previous 14 days), or another provoking factor described by the physician in the medical record (e.g., intravascular catheters). The remaining were classified as unprovoked events.

\section{Statistical analysis}

For each participant, person-years of follow-up were accrued from the date of enrollment in Troms $\emptyset$ 6 (2007-08) to the date of incident VTE, migration, death or the end of the study period (December 31, 2016), whichever occurred first. During follow-up, 630 participants were censored due to migration and 410 due to death. 
Crude incidence rates (IRs) with 95\% confidence intervals (Cls) were calculated and expressed as number of events per 1000 person-years. Cox proportional hazards regression models were used to estimate hazard ratios (HRs) with 95\% Cls for total VTE, provoked and unprovoked VTE, and for PE and DVT. HRs were estimated according to categories of the fraction of age-predicted CRF, by age- and sexspecific categories of eCRF and per MET increase. The lowest category was used as the reference in the categorical analyses. Age was used as the timescale, with the age at enrollment defined as entry time and the age at VTE or censoring defined as exit time. The analyses were performed in two models. The basic modelwas adjusted for age (as timescale) and sex, and the multivariable model was further adjusted for smoking, education, history of cardiovascular disease and history of cancer. The analyses of age- and sex-specific categories eCRF were not additionally adjusted for sex. Individuals ( $n=79$ ) with missing information on one or more covariates in the multivariable model were omitted from this analysis only. The impact of weight status on the association between eCRF and VTE risk was explored in analyses stratified according to $\mathrm{BMI}$-categories (i.e. $\mathrm{BMI}<25$ and $\mathrm{BMI} \geq 25$ ). Statistical interaction between eCRF and sex was tested by including the cross-product term in the proportional hazards regression model and no interaction was found. The proportional hazards assumption was evaluated and verified on the basis of Schoenfeld residuals. The statistical analyses were performed with STATA version 15.1 (Stata Corp, College Station, TX, USA).

\section{Results}

The mean age at baseline was $56 \pm 12$ years, and $53.1 \%$ of the participants were women. Overall, mean eCRF was $31.5 \pm 5.7 \mathrm{~mL} / \mathrm{kg} / \mathrm{min}$ in women and $38.8 \pm 6.8 \mathrm{~mL} / \mathrm{kg} / \mathrm{min}$ in men. Baseline characteristics according to categories of fraction of age-predicted CRF are shown in Table 1, and baseline characteristics according to age- and sex-specific categories of eCRF are shown in Table S3. Absolute eCRF increased with increasing categories from $29.0 \mathrm{~mL} / \mathrm{kg} / \mathrm{min}$ in those with eCRF $<85 \%$ of agepredicted to $43.2 \mathrm{~mL} / \mathrm{kg} / \mathrm{min}$ in those with eCRF $>100 \%$ of age-predicted. Women were 
overrepresented in the lowest category (71.2\%) and underrepresented in the highest category (19.6\%). While the mean age was similar across categories, the cardiovascular risk profile was more favorable in the higher categories of fraction of age-predicted eCRF. The fraction with higher education increased across the categories, while the fraction of current smokers was lowest in the highest category.

During 83,729 person-years of follow-up (median duration: 8.5 years, interquartile range: 8.28.9), there were 176 incident VTE events, yielding a crude IR of $2.1(95 \% \mathrm{Cl} 1.8-2.4)$ per 1000 personyears. Table 2 shows the characteristics of the VTE events. The mean age at incident VTE was $69 \pm 11$ years, and $55.1 \%$ of the events occurred in men. The most common clinical presentation was PE with or without concomitant DVT accounting for $56.3 \%$ of the events, and the remaining $43.7 \%$ were isolated DVTs. Further, $60.8 \%$ of the events were classified as provoked with cancer as the most frequent provoking factor (30.7\%).

Table 3 shows the association between the fraction of age-predicted CRF and VTE risk. Compared with those with eCRF $<85 \%$ of age-predicted, individuals with eCRF between $85-100 \%$ and $>100 \%$ of age-predicted values had $46 \%$ (HR $0.54 ; 95 \% \mathrm{Cl} 0.39-0.77$ ) and $67 \%$ (HR $0.33 ; 95 \% \mathrm{Cl} 0.20-$ 0.54) lower VTE risk, respectively, in the age- and sex-adjusted model. Significant associations of comparable strength were observed for all outcomes, although those with eCRF $>100 \%$ of agepredicted appeared to have a substantially lower risk of unprovoked VTE (HR $0.22 ; 95 \% \mathrm{Cl} 0.09-0.54$ ). The risk estimates were essentially unchanged after further adjustment for smoking, education, history of cardiovascular disease and history of cancer. Due to the unequal sex-distribution between the categories, the association between fraction of age-predicted CRF and the risk of total VTE was explored in sex-stratified Cox models. These showed similar trend as the main analyses, although a stronger association was suggested in women (Table S4). Each MET (approximately $3.5 \mathrm{ml} / \mathrm{kg} / \mathrm{min}$ ) increase in eCRF was associated with a significantly lower risk for all outcomes in the range $21-27 \%$.

The impact of weight status on the association between eCRF and VTE was explored in analyses stratified by BMI-categories (Fig. 1). Compared with the reference group (i.e. overweight/obese 
individuals with eCRF $<85 \%$ of age-predicted), the risk of VTE was $50 \%$ (HR 0.50 ; $95 \% \mathrm{Cl} 0.35-0.74$ ) lower among those in the same weight category but with eCRF $\geq 85 \%$ of age-predicted. For normal weight individuals with $\geq 85 \%$ of age-predicted eCRF, the risk was $55 \%$ lower ( $\mathrm{HR} 0.45 ; 95 \% \mathrm{Cl} 0.30$ 0.68), whereas normal weight individuals with $<85 \%$ of age-predicted eCRF had comparable VTE risk as the reference group (HR 1.06; 0.57-1.97).

HRs for the association between age- and sex-specific categories of eCRF and the risk of incident VTE are shown in Table S5. Compared with individuals with low eCRF, those with moderate and high levels had 37\% (HR 0.63; 95\% $\mathrm{Cl} 0.44-0.90)$ and 54\% (HR 0.46: 95\% $\mathrm{Cl} 0.32-0.68$ ) lower risks, respectively, in the age-adjusted model. The strongest associations were observed in relation to unprovoked VTE and PE. The corresponding risk reduction for those with moderate and high eCRF were 42\% (HR 0.58; 95\% $\mathrm{Cl} 0.34-1.01$ ) and 64\% (HR 0.36; 95\% Cl 0.19-0.67) for unprovoked VTE, and 39\% ( $\mathrm{HR} 0.61 ; 95 \mathrm{Cl} 0.39-0.96)$ and $63 \%$ ( $\mathrm{HR} 0.37 ; 95 \mathrm{Cl} 0.22-0.62)$ for PE. The risk estimates were essentially unchanged in after further adjustment for smoking, education, history of cardiovascular disease and history of cancer.

\section{Discussion}

In the present study of 10,393 participants recruited from the general population, we found that higher eCRF was associated with a lower risk of incident VTE. This finding was consistent across subcategories of VTE, and a beneficial association between high eCRF and VTE was observed in both normal weight and overweight/obese individuals.

To the best of our knowledge, the association between CRF and the risk of VTE has only been addressed in two previous studies. In a cohort of 777,925 men aged 18-20 years, Zöller et al. [34] found that one standard deviation increase in maximal workload on a cycle ergonometric test $\left(\mathrm{W}_{\max } / \mathrm{kg}\right)$ was associated with $19 \%$ lower risk of unprovoked VTE. A direct comparison with our findings is challenging due to different methodology, however, both studies support that a higher fitness level is associated 
with lower risk of incident VTE [34]. Our findings are also partly supported by Kunutsor et al. [35], who reported that men in the highest tertile of weight-adjusted CRF had a non-significant $20 \%$ lower risk of VTE. It was speculated that regression dilution due to a long follow-up (median: 25.2 years), limited statistical power and study population characteristics may have camouflaged an association [35]. In the present study, we extend previous findings by showing that eCRF was associated with lower VTE risk in individuals of both genders, through a wide age-range, across subcategories of VTE (i.e. unprovoked/provoked and DVT/PE) and in both normal weight and overweight/obese subjects.

We found that an eCRF $\geq 85 \%$ of age-predicted was associated with $46 \%$ lower risk, whereas eCRF $>100 \%$ of age-predicted was associated with $67 \%$ lower risk, compared with eCRF $<85 \%$ of agepredicted. Likewise, moderate $\left(20-60^{\text {th }}\right.$ percentile) and high $\left(>60^{\text {th }}\right.$ percentile) eCRF according to ageand sex-specific categories was associated with $37 \%$ and $54 \%$ lower VTE risk, respectively, compared with low eCRF $\left(<20^{\text {th }}\right.$ percentile). These risk estimates are somewhat larger than those observed in studies on physical activity and VTE, where risk reductions between $4 \%$ and $41 \%$ have been reported [12-15]. A stronger association between eCRF and VTE may be ascribed to several factors. First, information on habitual physical activity is commonly obtained through self-report [12-15], with an inherent chance of misclassification due to challenges with recall and social desirability [19]. In cohorts, such misclassification would be non-differential and presumably lead to underestimation of the true risk [42]. Thus, it is likely that the true association between physical activity and VTE is stronger than currently perceived. eCRF also comprises of additional components that are measured with a high level of precision, and that are well-established risk factors for VTE, such as waist circumference and age, which were the two most heavily weighted components in the eCRF algorithm. Obesity is associated with a two- to threefold increased risk of VTE, and among the obesity measures, waist circumference is reported to be the strongest predictor of VTE $[43,44]$. Further, although VTE may occur at all ages, the incidence increases exponentially with age, and the risk in those $\geq 85$ years is more than 12 -fold higher than in those aged 45 to 55 years $[3,17]$. Finally, as sizeable proportion of the variance in CRF may be ascribed to inherited factors, a highly active individual may have a relatively low level of fitness 
and vice versa $[21,45]$. Therefore, it has been suggested that physical activity and CRF may be considered as independent entities [31].

Analyses stratified by BMI-categories revealed that eCRF may alter the relationship between weight status and VTE risk. Specifically, we found that overweight and obese individuals with $\geq 85 \%$ of age-predicted eCRF had comparable VTE risk as normal weight individuals, and that the risk in normal weight individuals with eCRF $<85 \%$ was comparable to the risk in individuals with a high body weight. This suggests that the association between eCRF and VTE is independent of weight categories, and that higher eCRF may mitigate the elevated VTE risk in overweight/obesity. Similar observations have been made in relation to other major health outcomes, including all-cause and CVD-mortality, and CRF is also reported to influence the obesity paradox such that no paradox is observed in individuals who are classified as fit $[46,47]$. The present findings are in line with our previous report on physical activity and VTE risk, where we found that the association was only partly mediated by BMI (14-36\%), and concluded that the effect of physical activity on VTE risk primarily must be ascribed to mechanisms other than obesity [13].

The study by Zöller and colleagues [34] explored the role of familial components on the association between CRF and VTE risk. Attenuation of the risk estimates in analyses restricted to cousins and full-siblings suggested that the association was partly confounded by familial factors [34]. It is well established that the level of CRF in sedentary individuals and the ability to increase CRF with exercise demonstrate a high degree of familial aggregation and heritability. The familial resemblance of CRF is approximately $50 \%$, and the genetic component is estimated to be $20-30 \%$ in sedentary individuals $[21,45]$. There are also large inter-individual variations in the responses to exercise, with a familial resemblance of approximately 50\% [48]. The field of exercise genomics is still in its early stages, and characterized by underpowered and heterogeneous studies awaiting replication $[33,49]$. Although we currently are not aware of any genetic variants related to CRF that have been identified in genome- 
wide association studies of VTE, future adequately powered studies may investigate a potential causal association between CRF and VTE using a Mendelian randomization design [50-52].

At present, there is a lack of consensus on the definition of low, moderate and high levels of CRF [22]. Previous studies on CRF in relation to other health outcomes have used a variety of measures such as study-specific percentiles, age-specific cut-off values and absolute cut-offs $[23,28,53,54]$. In the present study, we found that higher eCRF was associated with lower VTE risk when expressed as a fraction of age-predicted values, age- and sex-specific categories and per MET increase. However, the former approach appeared to be superior as it was most strongly associated with VTE risk and was consistently associated with VTE risk across all subcategories. Considering CRF relative to the expected values for a healthy individual may not only be an easily communicable format in clinical and public health settings [55], but also facilitates for comparison between studies.

The main strengths of the present study include participants recruited from a general population with a wide age-range, high participation rates and a thoroughly validated outcome. The UNN is the only provider of relevant diagnostics and hospital care in the study region, and a near complete register may be anticipated. The present study is among the first to present data on the association between CRF and VTE risk, and provides highly relevant knowledge to field of lifestyle factors and VTE risk. A limitation of the study includes a substantial amount of exclusions (18\%) due to missing values on variables necessary to estimate CRF. Excluded participants were older and had a less favorable cardiovascular risk profile compared with those included. Although this may hamper the generalizability of our findings, it is unlikely to be a threat to the internal validity of the study. Furthermore, information on physical activity used in the eCRF algorithm was collected via self-report, with an inherent chance of information bias. However, given the prospective design of our study, this would be non-differential and tend to bias the association towards the null [42]. Finally, due to the observational design, there is a chance for residual confounding due to unknown confounders. 
In conclusion, we found that higher eCRF, obtained from easily available variables, was associated with a lower risk of incident VTE. The association was independent of weight status, suggesting that eCRF may counterbalance the elevated VTE risk associated with a high body weight.

\section{Addendum}

L. H. Evensen analyzed the data and drafted the manuscript. T. Isaksen collected data and revised the manuscript. S. K. Brækkan and J.-B. Hansen were responsible for conception and design of the study, data collection, and revision of the manuscript. The manuscript has been read and approved for submission to the Journal of Thrombosis and Haemostasis by all authors.

\section{Acknowledgements}

K. G. Jebsen TREC is supported by an independent grant from Stiftelsen Kristian Gerhard Jebsen.

\section{Disclosure of Conflicts of Interests}

L.H. Evensen, T. Isaksen, S.K. Brækkan and J.-B. Hansen report no conflict of interest. 


\section{References}

1 Glynn RJ, Rosner B. Comparison of risk factors for the competing risks of coronary heart disease, stroke, and venous thromboembolism. Am J Epidemiol 2005; 162: 975-82.

Arshad N, Isaksen T, Hansen JB, Braekkan SK. Time trends in incidence rates of venous thromboembolism in a large cohort recruited from the general population. Eur J Epidemiol 2017; 32: 299-305.

Heit JA. Epidemiology of venous thromboembolism. Nat Rev Cardiol 2015; 12: 464-74.

Kearon C. Natural history of venous thromboembolism. Circulation 2003; 107: I22-30.

Arshad N, Bjori E, Hindberg K, Isaksen T, Hansen JB, Braekkan SK. Recurrence and mortality after first venous thromboembolism in a large population-based cohort. J Thromb Haemost 2017; 15: 295-303.

ISTH Steering Committee for World Thrombosis Day. Thrombosis: a major contributor to the global disease burden. J Thromb Haemost 2014; 12: 1580-90.

Ng M, Fleming T, Robinson M, Thomson B, Graetz N, Margono C, Mullany EC, Biryukov S, Abbafati C, Abera SF, Abraham JP, Abu-Rmeileh NM, Achoki T, AlBuhairan FS, Alemu ZA, Alfonso R, Ali MK, Ali R, Guzman NA, Ammar W, et al. Global, regional, and national prevalence of overweight and obesity in children and adults during 1980-2013: a systematic analysis for the Global Burden of Disease Study 2013. Lancet 2014; 384: 766-81.

Stein PD, Hull RD, Kayali F, Ghali WA, Alshab AK, Olson RE. Venous thromboembolism according to age: the impact of an aging population. Arch Intern Med 2004; 164: 2260-5.

Torre LA, Siegel RL, Ward EM, Jemal A. Global Cancer Incidence and Mortality Rates and Trends--An Update. Cancer Epidemiol Biomarkers Prev 2016; 25: 16-27.

Kyu HH, Bachman VF, Alexander LT, Mumford JE, Afshin A, Estep K, Veerman JL, Delwiche K, lannarone ML, Moyer ML, Cercy K, Vos T, Murray CJ, Forouzanfar MH. Physical activity and risk of breast cancer, colon cancer, diabetes, ischemic heart disease, and ischemic stroke events: systematic review and dose-response meta-analysis for the Global Burden of Disease Study 2013. BMJ 2016; 354: i3857.

Warburton DE, Nicol CW, Bredin SS. Health benefits of physical activity: the evidence. CMAJ 2006; 174 : 801-9. activity may not reduce vascular disease risk as much as moderate activity: large prospective study of women in the United Kingdom. Circulation 2015; 131: 721-9. 

and risk of incident venous thromboembolism. J Thromb Haemost 2018; 16: 2208-17. Association between cardiovascular disease risk factors and occurrence of venous thromboembolism. A time-dependent analysis. Thromb Haemost 2012; 108: 508-15.

Olson NC, Cushman M, Judd SE, McClure LA, Lakoski SG, Folsom AR, Safford MM, Zakai NA. American Heart Association's Life's Simple 7 and risk of venous thromboembolism: the Reasons for Geographic and Racial Differences in Stroke (REGARDS) study. J Am Heart Assoc 2015; 4: e001494.

van Stralen KJ, Doggen CJ, Lumley T, Cushman M, Folsom AR, Psaty BM, Siscovick D, Rosendaal FR, Heckbert SR. The relationship between exercise and risk of venous thrombosis in elderly people. J Am Geriatr Soc 2008; 56: 517-22.

Tsai AW, Cushman M, Rosamond WD, Heckbert SR, Polak JF, Folsom AR. Cardiovascular risk factors and venous thromboembolism incidence: the longitudinal investigation of thromboembolism etiology. Arch Intern Med 2002; 162: 1182-9.

Evensen LH, Braekkan SK, Hansen JB. Regular Physical Activity and Risk of Venous Thromboembolism. Semin Thromb Hemost 2018; 44: 765-79.

Strath SJ, Kaminsky LA, Ainsworth BE, Ekelund U, Freedson PS, Gary RA, Richardson CR, Smith DT, Swartz AM, American Heart Association Physical Activity Committee of the Council on L, Cardiometabolic H, Cardiovascular ECR, Prevention Committee of the Council on Clinical C, Council. Guide to the assessment of physical activity: Clinical and research applications: a scientific statement from the American Heart Association. Circulation 2013; 128: 2259-79.

Caspersen CJ, Powell KE, Christenson GM. Physical activity, exercise, and physical fitness: definitions and distinctions for health-related research. Public Health Rep 1985; 100: 126-31.

McArdle WD, Katch FI, Katch VL. Exercise physiology: nutrition, energy, and human performance. 7th ed. Baltimore: Lippincott Williams \& Wilkins; 2010.

Ross R, Blair SN, Arena R, Church TS, Despres JP, Franklin BA, Haskell WL, Kaminsky LA, Levine BD, Lavie CJ, Myers J, Niebauer J, Sallis R, Sawada SS, Sui X, Wisloff U, American Heart Association Physical Activity Committee of the Council on L, Cardiometabolic H, Council on Clinical C, Council on E, et al. Importance of Assessing Cardiorespiratory Fitness in Clinical Practice: A Case for Fitness as a Clinical Vital Sign: A Scientific Statement From the American Heart Association. Circulation 2016; 134: e653e99. cause mortality. A prospective study of healthy men and women. JAMA 1989; 262: 2395-401. 

mortality and cardiovascular events in healthy men and women: A meta-analysis. JAMA 2009; 301: 2024-35. cardiorespiratory fitness in men aged 42 to 60 years with and without cardiovascular disease. Am J Cardiol 2009; 103: 1598-604.

Balady GJ, Arena R, Sietsema K, Myers J, Coke L, Fletcher GF, Forman D, Franklin B, Guazzi M, Gulati M, Keteyian SJ, Lavie CJ, Macko R, Mancini D, Milani RV, American Heart Association Exercise CR, Prevention Committee of the Council on Clinical C, Council on E, Prevention, Council on Peripheral Vascular D, et al. Clinician's Guide to cardiopulmonary exercise testing in adults: a scientific statement from the American Heart Association. Circulation 2010; 122: 191-225.

Nes BM, Vatten LJ, Nauman J, Janszky I, Wisloff U. A simple nonexercise model of cardiorespiratory fitness predicts long-term mortality. Med Sci Sports Exerc 2014; 46: 1159-65.

Artero EG, Jackson AS, Sui X, Lee DC, O'Connor DP, Lavie CJ, Church TS, Blair SN. Longitudinal algorithms to estimate cardiorespiratory fitness: associations with nonfatal cardiovascular disease and disease-specific mortality. J Am Coll Cardiol 2014; 63: 2289-96.

Nauman J, Nes BM, Lavie CJ, Jackson AS, Sui X, Coombes JS, Blair SN, Wisloff U. Prediction of Cardiovascular Mortality by Estimated Cardiorespiratory Fitness Independent of Traditional Risk Factors: The HUNT Study. Mayo Clin Proc 2017; 92: 218-27. Comparisons of leisure-time physical activity and cardiorespiratory fitness as predictors of all-cause mortality in men and women. Br J Sports Med 2011; 45: 504-10. physical activity patterns in predicting mortality in men. Am J Med 2004; 117: 912-8. VO2max trainability: a systematic review. BMC Genomics 2017; 18: 831. unprovoked venous thromboembolism in adulthood. Ann Med 2017; 49: 176-84. associated with risk of venous thromboembolism: a cohort study. Scand Cardiovasc J 2019: 1-4. 

Epidemiol 2012; 41: 961-7.

World Health Orgaization (WHO). Obesity: preventing and managing the global epidemic. Report of a WHO consultation. World Health Organ Tech Rep Ser 2000; 894: i-xii, 1-253. prediction model: the HUNT Study, Norway. Med Sci Sports Exerc 2011; 43: 2024-30. and cardiovascular risk factors in 4631 healthy women and men. Med Sci Sports Exerc 2011; 43: 146573. infarction is an independent risk factor for venous thromboembolism: the Tromso study. J Thromb Haemost 2008; 6: 1851-7.

Borch KH, Braekkan SK, Mathiesen EB, Njolstad I, Wilsgaard T, Stormer J, Hansen JB. Anthropometric measures of obesity and risk of venous thromboembolism: the Tromso study. Arterioscler Thromb Vasc Biol 2010; 30: 121-7. the etiology of deep vein thrombosis and pulmonary embolism: current epidemiological insights. Semin Thromb Hemost 2013; 39: 533-40. $\mathrm{JH}$. Familial resemblance for VO2max in the sedentary state: the HERITAGE family study. Med Sci Sports Exerc 1998; 30: 252-8. fitness as major markers of cardiovascular risk: their independent and interwoven importance to health status. Prog Cardiovasc Dis 2015; 57: 306-14. regarding fitness, fatness, and severity in the obesity paradox. J Am Coll Cardiol 2014; 63: 1345-54. aggregation of $\mathrm{VO}(2 \mathrm{max})$ response to exercise training: results from the HERITAGE Family Study. J App/ Physiol (1985) 1999; 87: 1003-8. 

for performance and health-related fitness phenotypes: the 2006-2007 update. Med Sci Sports Exerc 2009; 41: 35-73.

51 Bouchard C, Sarzynski MA, Rice TK, Kraus WE, Church TS, Sung YJ, Rao DC, Rankinen T. Genomic predictors of the maximal $\mathrm{O}(2)$ uptake response to standardized exercise training programs. J Appl Physiol (1985) 2011; 110: 1160-70.

52 Tregouet DA, Morange PE. What is currently known about the genetics of venous thromboembolism at the dawn of next generation sequencing technologies. Br J Haematol 2018; 180: 335-45.

53 Myers J, Prakash M, Froelicher V, Do D, Partington S, Atwood JE. Exercise capacity and mortality among men referred for exercise testing. N Engl J Med 2002; 346: 793-801.

54 Kim ES, Ishwaran H, Blackstone E, Lauer MS. External prognostic validations and comparisons of ageand gender-adjusted exercise capacity predictions. J Am Coll Cardiol 2007; 50: 1867-75. Standards for VO2 Max: Analysis from the Fitness Registry and the Importance of Exercise National Database (FRIEND Registry). Prog Cardiovasc Dis 2017; 60: 21-9. 


\section{Tables and Figures}

Table 1 Baseline characteristics of participants $(n=10,393)$ by categories of fraction of age-predicted cardiorespiratory fitness (CRF); the Troms $\varnothing$ Study (2007-2016).

\begin{tabular}{|c|c|c|c|}
\hline & $\begin{array}{c}\text { eCRF }<85 \% \\
(n=3,919)\end{array}$ & $\begin{array}{c}\text { eCRF } 85-100 \% \\
(n=4,508)\end{array}$ & $\begin{array}{c}\text { eCRF }>100 \% \\
(n=1,966)\end{array}$ \\
\hline eCRF $(\mathrm{mL} / \mathrm{kg} / \mathrm{min})$ & $29.0 \pm 4.8$ & $36.5 \pm 4.7$ & $43.2 \pm 5.7$ \\
\hline Age, years (mean, SD) & $57 \pm 12$ & $55 \pm 12$ & $57 \pm 12$ \\
\hline Sex, women $(\%, n)$ & $71.2(2,790)$ & $52.0(2,342)$ & $19.6(385)$ \\
\hline $\mathrm{BMI}, \mathrm{kg} / \mathrm{m}^{2}$ (mean, SD) & $29.5 \pm 4.4$ & $25.6 \pm 3.1$ & $24.1 \pm 2.6$ \\
\hline Triglycerides, mmol/L (mean, SD) & $1.74 \pm 1.16$ & $1.43 \pm 0.87$ & $1.25 \pm 0.74$ \\
\hline Total cholesterol, mmol/L (mean, SD) & $5.73 \pm 1.11$ & $5.54 \pm 1.08$ & $5.44 \pm 1.02$ \\
\hline HDL cholesterol, mmol/L (mean, SD) & $1.44 \pm 0.41$ & $1.54 \pm 0.45$ & $1.60 \pm 0.44$ \\
\hline Systolic blood pressure, $\mathrm{mmHg}$ (mean, SD) & $138 \pm 23$ & $132 \pm 22$ & $133 \pm 22$ \\
\hline Smoking $(\%, \mathrm{n})$ & $20.9(817)$ & $19.0(855)$ & $13.4(264)$ \\
\hline Higher education $+(\%, n)$ & $33.9(1,314)$ & $44.0(1,975)$ & $50.6(988)$ \\
\hline History of CVD $(\%, n)$ & $8.8(346)$ & $8.3(372)$ & $10.3(202)$ \\
\hline History of cancer $(\%, n)$ & $6.3(247)$ & $5.6(252)$ & $6.1(120)$ \\
\hline
\end{tabular}

BMI, body mass index; CVD, cardiovascular disease (angina pectoris, stroke, myocardial infarction); HDL, high-density lipoprotein; SD, standard deviation

†Fifteen or more year of education (corresponding to 3 years in university or academy)

Values are means \pm 1 SD or percentages with counts in parentheses 
Table 2 Characteristics of venous thromboembolism (VTE) events ( $n=176$ ); the Tromsø Study (2007-2016)

\begin{tabular}{lc}
\hline & $\%(\mathbf{n})$ \\
\hline Age, years (mean, SD) & $69 \pm 11$ \\
Sex (men) & $55.1(97)$ \\
Clinical characteristics & \\
Pulmonary embolism & $56.3(99)$ \\
Deep vein thrombosis & $43.7(77)$ \\
Provoked & $60.8(107)$ \\
Unprovoked* & $39.2(69)$ \\
Provoking factors† & \\
Surgery & $17.1(30)$ \\
Trauma & $11.4(20)$ \\
Acute medical condition & $9.1(16)$ \\
Cancer & $30.7(54)$ \\
Immobilization $\ddagger$ & $14.2(25)$ \\
Other§ & $6.8(12)$ \\
Clinical risk factors & \\
Estrogens (HRT, oral contraceptives) & $3.8(3)$ \\
Heredity 9 & $4.0(7)$ \\
Pregnancy/postpartum & $1.1(2)$ \\
Other medical conditions** & $21.3(23)$ \\
\hline
\end{tabular}

HRT, hormone replacement therapy; SD, standard deviation; VTE, venous thromboembolism

*No provoking factors at the time of diagnosis

tOne patient may have multiple provoking factors

$\ddagger$ Bed rest $\geq 3$ days, long-distance travel $\geq 4 \mathrm{~h}$ within the previous 14 days, or confined to wheelchair

§Other factors specified as provoking in the medical record (e.g., intravascular catheters)

१Reported family history of VTE in first-degree relative(s) before the age of 60

**Other diseases within the previous year (myocardial infarction, ischemic stroke heart failure, inflammatory bowel disease, or myeloproliferative disorders)

Values are means \pm 1 SD or percentages with counts in parentheses 
Table 3 Incidence rates (IRs) and hazard ratios (HRs) with 95\% confidence intervals (Cls) of venous thromboembolism (VTE) according to percentage of age-predicted cardiorespiratory fitness (CRF); the Troms $\varnothing$ Study (2007-2016)

\begin{tabular}{|c|c|c|c|c|c|}
\hline $\begin{array}{l}\text { Fraction of age- } \\
\text { predicted CRF }\end{array}$ & $\begin{array}{c}\text { Person- } \\
\text { years }\end{array}$ & VTE events & Crude IR $(95 \% \mathrm{CI})$ & HR $(95 \% \mathrm{Cl}) *$ & $\mathrm{HR}(95 \% \mathrm{Cl})^{\dagger}$ \\
\hline \multicolumn{6}{|l|}{ Total VTE } \\
\hline$<85 \%$ & 31339 & 94 & $3.00(2.45-3.67)$ & 1 & 1 \\
\hline $85-100 \%$ & 36438 & 60 & $1.65(1228-2.12)$ & $0.54(0.39-0.77)$ & $0.54(0.39-0.76)$ \\
\hline$>100 \%$ & 15951 & 22 & $1.38(0.91-2.09)$ & $0.33(0.20-0.54)$ & $0.33(0.20-0.54)$ \\
\hline Per 1 MET & 83729 & 176 & $2.10(1.81-2.44)$ & $0.75(0.67-0.83)$ & $0.75(0.67-0.83)$ \\
\hline \multicolumn{6}{|l|}{ Provoked VTE } \\
\hline$<85 \%$ & 31339 & 57 & $1.82(1.40-2.36)$ & 1 & 1 \\
\hline $85-100 \%$ & 36438 & 34 & $0.93(0.67-1.31)$ & $0.53(0.34-0.82)$ & $0.52(0.33-0.81)$ \\
\hline$>100 \%$ & 15951 & 16 & $1.00(0.61-1.64)$ & $0.41(0.23-0.75)$ & $0.41(0.23-0.75)$ \\
\hline Per 1 MET & 83729 & 107 & $1.28(1.06-1.54)$ & $0.76(0.66-0.87)$ & $0.76(0.66-0.87)$ \\
\hline \multicolumn{6}{|l|}{ Unprovoked VTE } \\
\hline$<85 \%$ & 31339 & 37 & $1.18(0.86-1.63)$ & 1 & 1 \\
\hline $85-100 \%$ & 36438 & 26 & $0.71(0.49-1.05)$ & $0.58(0.34-0.97)$ & $0.57(0.34-0.96)$ \\
\hline$>100 \%$ & 15951 & 6 & $0.38(0.17-0.84)$ & $0.22(0.09-0.54)$ & $0.22(0.09-0.53)$ \\
\hline Per 1 MET & 83729 & 69 & $0.82(0.65-1.04)$ & $0.73(0.62-0.87)$ & $0.73(0.61-0.86)$ \\
\hline \multicolumn{6}{|c|}{ Pulmonary embolism } \\
\hline$<85 \%$ & 31339 & 51 & $1.63(1.24-2.14)$ & 1 & 1 \\
\hline $85-100 \%$ & 36438 & 35 & $0.96(0.69-2.14)$ & $0.56(0.36-0.88)$ & $0.55(0.35-0.86)$ \\
\hline$>100 \%$ & 15951 & 13 & $0.81(0.47-1.40)$ & $0.32(0.17-0.61)$ & $0.32(0.17-0.61)$ \\
\hline Per 1 MET & 83729 & 99 & $1.18(0.97-1.40)$ & $0.72(0.62-0.83)$ & $0.72(0.62-0.83)$ \\
\hline \multicolumn{6}{|c|}{ Deep vein thrombosis } \\
\hline$<85 \%$ & 31339 & 43 & $1.37(1.02-1.85)$ & 1 & 1 \\
\hline $85-100 \%$ & 36438 & 25 & $0.67(0.46-1.02)$ & $0.53(0.32-0.88)$ & $0.52(0.31-0.87)$ \\
\hline$>100 \%$ & 15951 & 9 & $0.56(0.29-1.08)$ & $0.35(0.16-0.75)$ & $0.35(0.16-0.75)$ \\
\hline Per 1 MET & 83729 & 77 & $0.92(0.74-1.15)$ & $0.79(0.67-0.93)$ & $0.79(0.67-0.93)$ \\
\hline
\end{tabular}

MET, metabolic equivalent $(3.5 \mathrm{~mL} / \mathrm{kg} / \mathrm{min})$

*Adjusted for age (as timescale) and sex.

TAdjusted for age (as timescale), sex, smoking, education, history of cardiovascular disease and history of cancer. 
Figure 1 Incidence rates (IRs) and hazard ratios (HRs) with 95\% confidence intervals (Cls) of venous thromboembolism (VTE) by percentage of age-predicted cardiorespiratory fitness (CRF) and weight status; the Troms $\varnothing$ Study (2007-2016). The regression model is adjusted for age (as timescale) and sex.

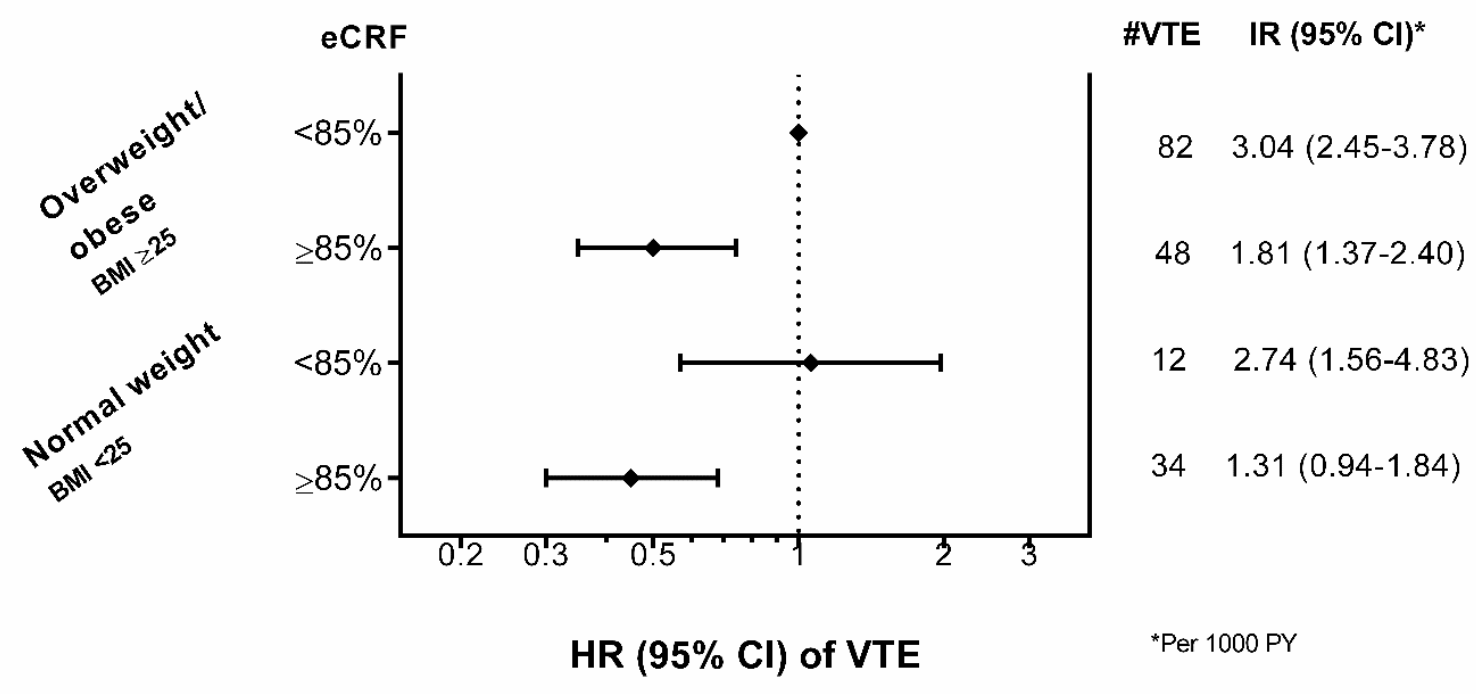

